\title{
Using Social Networks to Support Software Ecosystems Comprehension and Evolution
}

\author{
Rodrigo Pereira dos Santos, Maria Gilda P. Esteves, \\ Gleisson de S. Freitas, Jano Moreira de Souza \\ System Engineering and Computer Science, COPPE, University of Rio de Janeiro, Rio de Janeiro, Brazil \\ Email: rps@cos.ufrj.br, gilda@cos.ufrj.br, gleisson@cos.ufrj.br, jano@cos.ufrj.br
}

Received December 23, 2013; revised January 23, 2014; accepted February 13, 2014

Copyright (C) 2014 Rodrigo Pereira dos Santos et al. This is an open access article distributed under the Creative Commons Attribution License, which permits unrestricted use, distribution, and reproduction in any medium, provided the original work is properly cited. In accordance of the Creative Commons Attribution License all Copyrights (C) 2014 are reserved for SCIRP and the owner of the intellectual property Rodrigo Pereira dos Santos et al. All Copyright (C) 2014 are guarded by law and by SCIRP as a guardian.

\section{ABSTRACT}

The software industry has evolved to a multiple-product development created on a platform and based on a common architecture integrated to other systems. This integration happens through components and third-party developers networks in Software Ecosystems (SECOs). Since systems and software development processes present challenges beyond the technical side, SECOs have emerged as an approach to improve the Software Engineering (SE) mindset in the industry. This fact changes the software industry as it requires the management of an integrated social-based environment to support a transition from an intra-organizational to an open business model approach towards a SECO approach. In this context, social networks can be important to coordinate a collaborative and distributed environment to develop SECOs platforms. This paper analyses the impact of social networks in SECOs through an integrated framework of the SECO and social network challenges. So, a proposal for a sociotechnical-based architecture to support the SECOs lifecycle is discussed.

\section{KEYWORDS}

\section{Software Ecosystems; Social Networks; Software Life Cycle; Innovation}

\section{Introduction}

The development of information systems faces challenges that lie beyond the purely technical perspective. According to Bosch [1], this scenario requires professionals in the software industry that develop approaches to manage its consequences in the product and process complexity. Thus, developing an information system as a unique software product has been replaced by the development of multiple products. These products derive from a platform based on a common architecture and integrated with other systems via networks of software components and stakeholders worldwide [2]. In this sense, the study of Software Ecosystems (SECOs) rises as a research topic in Software Engineering (SE) [3,4]. SECOs represent an approach to improve the comprehension of SE in an inter-organizational context as it focuses on the concept of a common platform based on reuse. SECOs also involve users and external developers in the software development process to open and evolve platforms in a decentralized way [5].

Collaboration, communication and coordination mechanisms are required to develop SECOSs platforms through the computer-supported cooperative work (CSCW). So, some research works focus on the need of technologies to manage the collaborative development process for software in SECOs [6,7]. Amongst these technologies, social network sites are emerging as a new opportunity, i.e., Web 2.0 platforms, where people communicate with each other. In the SECO context, these sites can be extended to create networks of software artifacts and actors (developers), named socio-technical networks [8]. That is, software artifacts such as code, components, services, models, or documents can interact with actors and with other artifacts. These interactions highlight the importance of the associated documentation, more than that the teams involved in their creation [9].

In spite of the benefits, how social network technolo- 
gies can support the development of platforms in SECOs is a challenge, considering the aspects of CSCW, global $\mathrm{SE}$, and free and open source software (FOSS). The set of tools provided by social network sites can be organized to explore some solutions [7]. As pointed by Jansen et al. [3], social technologies should be evaluated, customized and integrated to SE environments and tools. In this sense, this paper analyses the impact of social networks in SECOs through an integrated framework of the SECO and social network challenges. A proposal for a sociotechnical architecture for the SECOs lifecycle is presented, based on open innovation and FOSS. In this sense, socio-technical networks are graphs of nodes (actors and artifacts) and edges (their dependencies). In turn, sociotechnical networks extend them to contemplate a multidisciplinary view, including other elements to analyze SECOs facts and artifacts based on the actor-network theory [10].

This paper corresponds to an extended version of the work of Santos et al. [11], published in the I Brazilian Workshop on Social Network Analysis and Mining (BraSNAM). Apart from this introduction, the paper has the following sections: Section 2 covers the theoretical basis (SECOs and social networks); Section 3 discusses some related work; Section 4 presents a discussion on the impact of social networks in SECOs; and Section 5 concludes the paper and points out to future work.

\section{Background}

Since the treatment of economic and social issues is crucial for SE [12], the SECO perspective has led the main players in the software industry to reconsider their operating practices. They also need to open their platforms to external entities in order to guarantee the business goals and keep up with the speed of market innovation. However, the goal in SECO research is even broader, encompassing different facets of SE, such as software reuse, system architectures, CSCW, social networks, sociotechnical networks, software quality, and economics. So, this section presents the background of the SECO and of the social networks.

\subsection{Software Ecosystems}

A trend in SE consists of analyzing the birth, development, maturing, and eventual "death" of wider systems or platforms. In this case, the traditional boundaries between the entities in the development process have been deconstructed (or adjusted) to allow collaboration and interoperability amongst the parties [13]. According to Messerschmitt \& Szyperski [14], these systems have been a research topic in the community, named SECOs. According to Jansen et al. [3], a SECO represents a set of businesses functioning as a unit and interacting with a shared market for software and services, based on a common technological platform or market and operating through the exchange of information, resources and artifacts.

Some examples are the MySQL/PHP SECO, the Microsoft SECO, and the iPhone SECO. These examples can be used to establish the typical characteristics of the SECOs. A SECO can be contained in other SECOs, such as the Microsoft SECO CRM, contained in the full Microsoft SECO. On the other hand, the iPhone SECO, with its AppStore, is a closed SECO, whereas the MySQL/PHP SECO is open, as the organizations have access to the source code and related knowledge bases. Well-known organizations, including Microsoft, Amazon, Nokia, Google, SAP, and Apple, lead the development of SECOs as pioneers. This contributes to the SECO research status, essentially conceived from the movements of the software and services industry. The main reason is that software vendors no longer work as independent units that deliver separate products, but have rather become increasingly more dependent of other vendors. The dependencies refer to the use of vital components and infrastructures, e.g., operating systems, libraries, and component and platform markets [15].

Software vendors resort to a virtual integration through alliances that establish networks of influence and interoperability, naturally generating the SECOs. However, some challenges also emerge [16]: 1) vendors need to be aware of the SECOs; 2) they want to have a perception of the survival strategies amongst the participants of their SECOs; and 3) they still need a general view of how the organization can open its platform to the SECO without losing intellectual property. Jansen et al. [16] modeled SECOs on three levels, as shown in Figure 1. The first level, named organizational (independent software vendor, or ISV), aims at studying the actors and their relationships in the context of the organization inserted in a SECO. The goal is to study performance and evolution as factors related to SECO stakeholders. The opening process is a key issue, considering aspects of knowledge sharing with partners.

On the second level, of software supply networks (SSNs), the objects of study are the networks within a SECO, as well as the relationships between them. The goal is to analyze the participants (e.g., vendors, clients, external developers) and the internal characteristics related to SECO health and stability (i.e., size, type, roles, connectivity etc.). Finally, the objects of study of the third level are the SECOs themselves, including the relationships between them. In this context, SECOs should have their boundaries well defined, such as a market, a technology, a platform, or a firm, even if overlapped. Geographical restrictions, component specifications, availability of licenses, and the age and history of the 


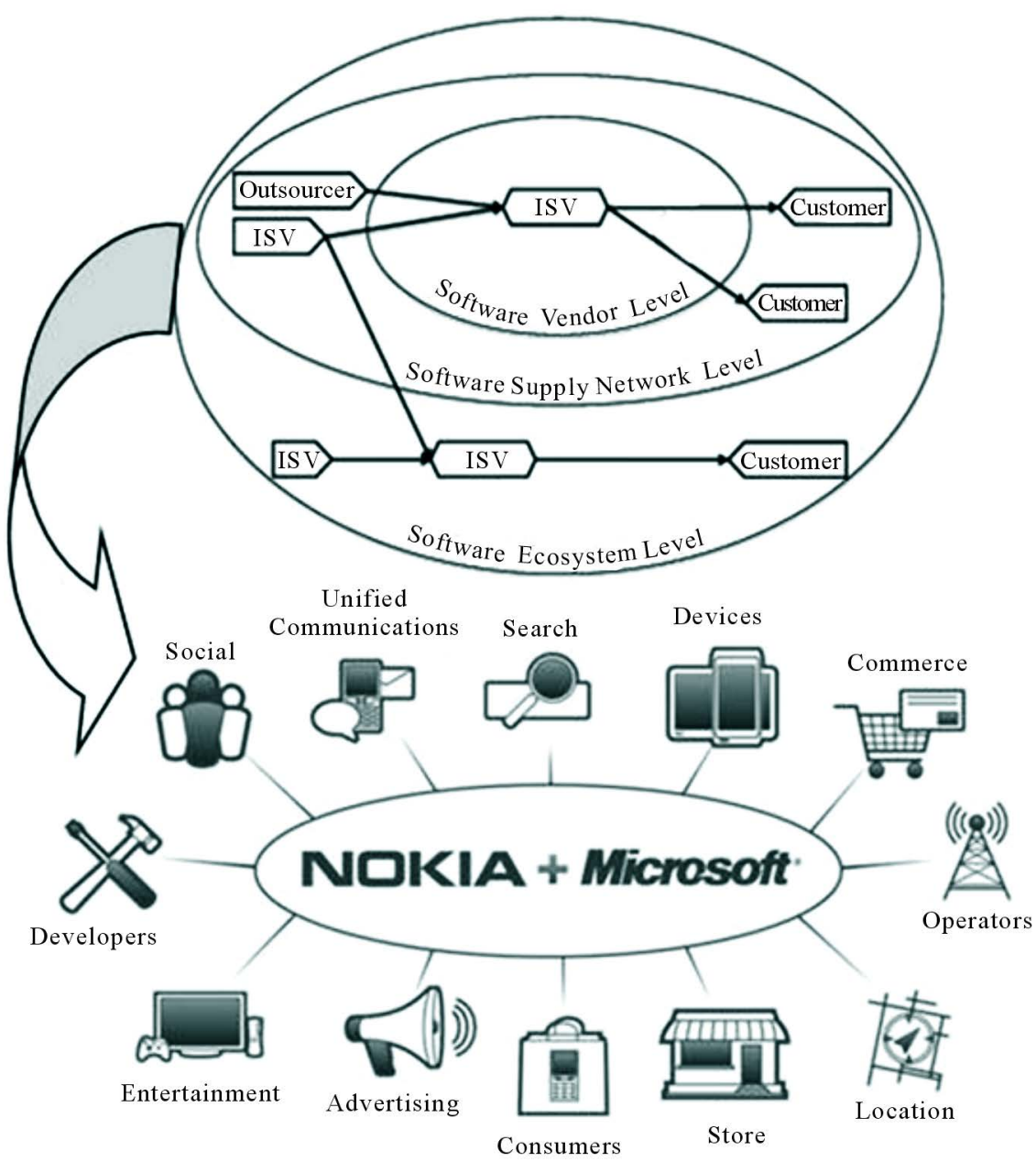

Figure 1. SECOs scope levels and an example of intersection between the Nokia SECO and the Microsoft SECO to create a new SECO. Sources: $[3,17]$.

SECOs are also important. Thus, the SECOs lifecycle can be synthetized in four stages [16]:

1) The establishment of a market relationship with a dominant and focused organization;

2) The creation of a preliminary network;

3) The reduction of the focused organization's power, and the stimulus of new communities of practice; and

4) The existence of a community of creation, where there is no dominant organization and the power is distributed by the communication/participation of other ISV and SSN members, including consumers and users.

From a three-dimensional perspective, Campbell \& Ahmed [13] state that the SECO concept emerged from the theories used to develop similar architectures and social networks. As a result, it is a new metaphor to understand the transition, evolution, and innovation in the SE process. The three SECO dimensions are so established, where the latter one is the goal of the present research: architecture, business, and social [2]. The social dimension is focused on understanding the organizational opening process as a whole from the communities created around the SECOs platforms (collaborative development). It is driven by three factors:

- Utilitarianism - compensation and rewards expected and received, financial or not;

- Promotion-implicit or explicit recognition of the capabilities and skills of the collaborator, i.e., person that contributes to the SECO community; and

- Gain in knowledge-storing and maintaining experiences, and opportunities for the parties interested in getting involved with new technologies and tools in a collaborative environment.

\subsection{Social Networks, Social Software and Innovation}

A social network consists of a set or group of people with some pattern of connection or interaction between them [18]. The graph theory has been used in the analysis of the social networks to check the social relations through graphs (sociograms). In this case, each connection be- 
tween two points or nodes represents a relationship between pairs of individuals [19], and the edges are the specificities in the relationships. One of the first examples that prove the world is increasingly interconnected and smaller was the Milgram's experiment. Milgram's "six degrees" theory, as it was named, lies in the fact that two people distributed in the world have only a small number of intermediary connections, approximately six degrees of separation [20]. The Internet and other technologies that support social networks such as Facebook, Twitter, and Google+, contribute to reduce the distances between people and increase the number of connections in the network. In a recent study produced by Facebook, it was found that the average degree of separation between two users is 4.74. When done in countries such as the US, Sweden, or Italy, the number of intermediary connections fell to 3.74 [21].

In the early 1990s, the expression "social software" was created by specialist groups [22], defined as any website or application that connects people with similar interests and ideas, via Web [23]. Its main motivation was the demand for functionalities that would allow people to connect through computers. Butterfield [24] says that social software combines devices that allow: creation of identity; identification of presence; establishing of relationships; conversation; and formation of groups (i.e., communities of interest). Webb [25] added two items to the original list: reputation, which allows the recognition of the personal status in a social network, and sharing, which allows the exchange of data and information, e.g., documents, photographs, videos, and links. This contributed for the concept of social networks, which started being defined by a representation of entities (e.g., people, companies), connected to each other via specific relations [19].

Social network sites have been used to represent information systems with a large quantity of elements (people, points-of-sale, entities, equipment etc.) and their connection [26]. They allow people, groups and organizations to carry out collaborative work through Web pages, online workgroups, and communities. An advantage is the visibility and mapping of connections between people, or between people and organizations. It is possible to access the knowledge of the members in a network, and sometimes their contacts'. This derived the concept of viral potential as a tool of social media and marketing as it has been used to connect people to the challenges of the corporate world. It also closes the gap between organizations and their stakeholders through communication channels that link agents, vendors, developers, and clients.

In relation to the business world, the social networks work as word-of-mouth dissemination, where consumers spread perceptions on products and services, but with a bigger power of propagation. For example, Facebook has applications such as the Like Store where any user can change a page in a virtual shop, exploring recommendation and social marketing mechanisms. Thus, companies may not overcome the higher barriers when they do not keep up with the innovation speed in their social-based markets [27]. However, new products or services do not appear in a spontaneous way. It is necessary to have research and development (R\&D) institutes with the creation of new market niches and the trading of new products. Also, the network effect forces companies to take more products to the market in shorter cycles. Outsourcing strategies and more flexible product lines may also help [28]. In the SECO reality, the use of social networks can stimulate the innovation process as an additional strategic mechanism to create novelty (i.e., product or service), as it meets two requirements:

1) the novelty generates social gain as it allows a greater range of goods and services to be delivered to the society;

2) the novelty produces returns (financial and others) to the innovator as it is consumed by the society.

\section{Related Work}

The global software development beyond the organizational boundaries introduces new challenges to traditional SE processes, requiring a collaborative effort from several actors. Changes happen from a centralized to a decentralized management, which deconstructs the traditional intra-organizational software product line. It also involves new business models to support an open requirements engineering, with a collaborative process where clients suggest and vote for new features [16].

Seichter et al. [7] propose the use of social networks functionalities in the SECOs domain, specifying different types of relationships between artifacts and actors. In this case, the artifact should have a status of "first-class citizen" in an artifact sharing ecosystem. The goal is twofold: exchanging tacit knowledge between the different SECOs levels, and facilitating a software development artifacts management. Dealing with the shared and distributed knowledge becomes the SECOs challenge: 1) whenever new actors start participating in a SECO, the complex dependencies between shared artifacts should be informed to them in such a way; and 2) as the actors can leave the SECO at any time, this is associated to a loss of information.

Possible scenarios are discussed in order to propose a prototype for social network sites to support the social lifecycle of SECOs. The idea is to allow new actors to obtain the information for their engagement. Also, it helps reducing the "knowledge drain" when one or more actors/artifacts leave, aiming at making the knowledge 
visible. There are eight social elements that support a SECO in the construction of a "social network site", making the sociotechnical network feasible [7]: Profile; Wall; New Feeds; Data Sharing; Teaming; Searching; Suggestion; and Messaging.

Besides, the communication in a sociotechnical network is focused on the knowledge the actors wish to share amongst themselves, but also on the artifacts exchange with one another (e.g., software components) and with the other SECO actors. Thus, some social benefits appear: the reuse of artifacts, the generation of a new product, communication, and updates (Table 1). According to Seichter et al. [7], social networks sites in SECOs allow the visualization of the flow of knowledge and the understanding of the actors' tacit knowledge. It also promotes an easy artifacts management as it relates actors to tools/artifacts such as architecture, components, and products.

In parallel, Seichter et al. [7] analyze how artifacts can relate to SECO actors through four modes:

- Owned by: relates an artifact to its owner(s) or the actor who has the knowledge about it. The goal is to make it visible to the other stakeholders and so reduce the loss of knowledge when actors leave the ecosystem;

- Interested in: allows an actor (or groups of actors) to be informed on status updates, or when new data is published by an artifact through new feeds, messages and comments from other actors who have the same interest;

- Depends on: occurs in platform development when many artifacts depend of others. Using social networks helps visualizing these dependencies in the SECOs, adding value through new feeds or messages; and

- Member of: classifies SECO actors and artifacts in groups of interest as it happens in the online social network sites, linking developers, users, models, code, services or documentation in a single context.

Begel et al. [29] presented a proposal for the construction of a social network for codes named Codebook. The authors also proposed a framework for social network in the Web in order to help software developers to hold connections with their peers. Codebook aims at discovering the relations between people, codes, bugs, test cases, specifications, and other related artifacts through the mining of any type of software repository. It can be tailored to specific uses (e.g., managers with an in-depth knowledge of the team and the software).

On the other hand, Capuruço \& Capretz [6] proposed a model for a Social Ecosystem Recommender. This recommender includes modules that manage the time and context dependencies and suggest interactions among the members. Despite the progress in applying the recommender, the model is restricted to the relations among the actors, considering their relations through time and in the context they occur in. Therefore, the authors did not model any kind of artifact related to the members, or even foresee an extension to identify proximity between actors and artifacts.

\section{The Social Network Oriented Discussion of SECOs}

The range of social networks opportunities incites the organizations to act and interact beyond their boundaries, through the creation of groups or communities related to their business. Since the resources to connect people based on common interests form these networks, social network sites can expand the SECOs social capital, as a social media or as a channel for communication and marketing. So, these sites can approximate software components, products and services, as well as stakeholders. This section discusses the use of social network concepts and technologies considering the SECOSs challenges, as well as a proposal for a sociotechnical based architecture to support the SECOs lifecycle, based on this discussion.

\subsection{Analyzing Social Networks Sites in the Context of the SECOs Challenges}

From the state-of-the-art described in Section 3, this

Table 1. Types of interaction between networks of actors and networks of artifacts. Adapted from [7,29].

\begin{tabular}{ll}
\hline Interaction & Example \\
\hline Actors $\rightarrow$ Actors & $\begin{array}{l}\text { Actors can communicate among themselves via publications, data sharing, messages, and groups (communities). } \\
\text { This can influence the SECO considering suggestions, evaluations, assessments, and comments. } \\
\text { Actors can interact with artifacts as they interact with others in a social network site. This includes classification } \\
\text { and comments in a change of status, enriching it with public domain information and providing a return to direct } \\
\text { interactions with users, developers, vendors, or owners. }\end{array}$ \\
Artifact $\rightarrow$ Actors & $\begin{array}{l}\text { Due to the promotion to "first-class citizen", any change in the artifact status is visible through new feeds and } \\
\text { messages to the actors who are connected to it (i.e., repositories, version control or bug control systems). }\end{array}$ \\
Thiftifact & $\begin{array}{l}\text { This type of interaction can be disseminated through the publicizing of information and the automatic interpretation } \\
\text { of the dependency between artifacts. }\end{array}$ \\
\hline
\end{tabular}


work initially aims at studying the use of online social networks to improve the SECOs social capital. The idea is to strengthen relationships among the concepts and produce the "glue" that holds the actors connected by virtual communities. The analysis confronted the technical and business challenges faced by the SECOs, as presented by Jansen et al. [3], aimed at acquiring an environment for a sociotechnical network. These challenges were grouped considering the three scope levels of the SECOs (Section 2.1). However, only the most relevant challenges were analyzed, i.e., those related to the social networks. Table 2 shows the integrated framework of the SECO and social network challenges, discussed in the following paragraphs.
On the organizational level (ISV), focused on the organization that creates, models and programs software functionalities within the SECOs, where five challenges were listed: 1) establishing and maintaining relations between vendors and buyers active, as it happens among friends in a social network; 2) creating a portfolio and product line planning; 3) determining how much knowledge and software will be shared and reused as open code functionality, which requires clear guidelines related to the types of software and underlying licenses; 4) developing an architecture based on extensibility, portability, and variability; and 5) developing integration systems in the organization.

On the SSN level, the focus in on the connections

Table 2. An integrated framework of the SECO and social network challenges. Extended from Jansen et al. [3].

\begin{tabular}{|c|c|c|c|}
\hline Levels & Challenges & Benefits of the social network & Elements of the site \\
\hline \multirow{4}{*}{ ISV } & $\begin{array}{l}\text { Challenge \#1 } \\
\text { Establishment of relationships }\end{array}$ & $\begin{array}{l}\text { 1. To keep the relations with potential buyers and } \\
\text { vendors alike. }\end{array}$ & $\begin{array}{l}\text { New feeds, messages, comments, } \\
\text { and forums }\end{array}$ \\
\hline & $\begin{array}{l}\text { Challenge \#2 } \\
\text { Portfolio and product line planning }\end{array}$ & $\begin{array}{l}\text { 1. To show the organization, services and products, } \\
\text { and actions, present and future; } \\
\text { 2. To decide when and whether it is worth to publish } \\
\text { a new functionality; } \\
\text { 3. To assess the reuse patterns. }\end{array}$ & Creation of Web pages and forums \\
\hline & $\begin{array}{l}\text { Challenge \#3 } \\
\text { Knowledge management }\end{array}$ & $\begin{array}{l}\text { 1. To publish information on software artifacts that } \\
\text { can be reused in the SECO; } \\
\text { 2. To set guidelines for developers related to software } \\
\text { reuse and licenses, and publicize information on how } \\
\text { the software will be made available; } \\
\text { 3. Establish feedback for the other actors, e.g., } \\
\text { descriptions of bugs. }\end{array}$ & $\begin{array}{l}\text { Profiles, Web pages, groups, } \\
\text { new feeds, and messages }\end{array}$ \\
\hline & $\begin{array}{l}\text { Challenge \#5 } \\
\text { Development of organizational } \\
\text { integration systems }\end{array}$ & $\begin{array}{l}\text { 1. To promote requirements engineering in a } \\
\text { participative environment; } \\
\text { 2. To assist in the requirement prioritization processes; } \\
\text { 3. To generate feedback. }\end{array}$ & $\begin{array}{l}\text { Publications in profiles, Web pages } \\
\text { or groups, evaluation by actors in } \\
\text { the network, and comments }\end{array}$ \\
\hline \multirow{3}{*}{ SSN } & $\begin{array}{l}\text { Challenge \#1 } \\
\text { Establishiment of relationships }\end{array}$ & $\begin{array}{l}\text { 1. To establish different sale and distribution channels, } \\
\text { their main competitors and potential partners; } \\
2 \text {. To attract and allow software developers to choose } \\
\text { when they wish to become active in a SECO; } \\
\text { 3. To allow organizations to present themselves to } \\
\text { potential buyers or vendors. }\end{array}$ & $\begin{array}{l}\text { Request for friendship, new feeds, } \\
\text { publication on the wall, messages, } \\
\text { groups, "shops", and forums }\end{array}$ \\
\hline & $\begin{array}{l}\text { Challenge \#2 } \\
\text { Quality management }\end{array}$ & $\begin{array}{l}\text { 1. To allow the consumer to approve a given product } \\
\text { or software; } \\
\text { 2. To enable the exchange of experiences among actors, } \\
\text { facilitating learning, interaction, and quick feedback. }\end{array}$ & $\begin{array}{l}\text { Forums, messages, comments, } \\
\text { evaluations, and ranking }\end{array}$ \\
\hline & $\begin{array}{l}\text { Challenge \#3 } \\
\text { Open innovation }\end{array}$ & $\begin{array}{l}\text { 1. To allow clients and partners to demand and/or } \\
\text { develop new solutions and trade them in a software } \\
\text { component shop. }\end{array}$ & $\begin{array}{l}\text { Open calls on the company wall, } \\
\text { messages sent to its social network } \\
\text { through the profile or Web pages for } \\
\text { companies, and "shops" }\end{array}$ \\
\hline SECOs & $\begin{array}{l}\text { Challenge \#1 } \\
\text { Development of policies and strategies } \\
\text { for the orchestration of SECOs }\end{array}$ & $\begin{array}{l}\text { 1. To establish communication, marketing and } \\
\text { feedback channels for actors and artifacts; } \\
2 \text {. To facilitate the development of a business model } \\
\text { based on the relationship amongst the many levels } \\
\text { and through the use of "social software”, available } \\
\text { in social network sites. }\end{array}$ & $\begin{array}{l}\text { Use of all the existing functionalities } \\
\text { and development of specific } \\
\text { applications for each SECO }\end{array}$ \\
\hline
\end{tabular}


among software, hardware, and organizational services, in order to meet the market demands. This level has three challenges: 1) how a developer (vendor) should choose when to become active in the social network and so visualize potential buyers and suppliers via the profile notice board, where data is publicized; 2) how vendors and buyers receive this information through the new feeds (as updates of friends in social networks); and 3) how clients and partners create new solutions and can commercialize them within the SECOs.

Finally, on the SECOs level, three challenges are pointed by Jansen et al. [3], but only the first one was considered in the analysis: 1) creating policies and strategies to orchestrate social participation on the many levels of the SECOs in a balanced manner; 2) characterizing and building a business model for the SECOs; and 3) modeling the sociotechnical network and generating value from the use of social software and from the creation of an fertile environment to connect people and artifacts through the Internet.

\subsection{The Sociotechnical Based Proposal for the SECO Lifecycle}

Considering the analysis presented in Section 4.1, the SECOs context shows the pressure organizations face to open up their platforms. This paradigm shift has affected the relationship of the organizations with the SSN, generating a transition from an intra-organizational to an open business model towards a SECO approach. The need lies in the creation of a business model that supports the entry of new actors and artifacts in the SECOs, in a global and scalable way. This research proposes the use of existing online social network sites, such as available functionalities and resources, and recommender algorithms. The goal is to increase the interaction among actors and artifacts, adding value to their relationships in a sociotechnical network. In this sense, social network sites can allow the registration and interaction between SECOs actors and artifacts, on both organizational and SSN levels. Both actors and artifacts have been raised to the status of "first-class citizens" and, therefore, both are objects in the formation of social networks in SECOs.

The results of the analysis were combined with the "Online Crowds" model of Russ [30] and also with the stages of the SECOs lifecycle (Section 2.1). Russ' model is based on the fact that it is fundamental to understand the effect of the social contagion process in the formation of online crowds. This way, he describes the process of social network formation, dividing it into four stages: initiation, propagation, amplification, and termination. This research proposes a lifecycle for the use of social network sites in SECOs from an extension of the Russ' model, also considering stages (Figure 2):

1) Initiation: creation of a Web page in a social network site, on an organizational level (ISV), aiming at i) establishing a market relation with the stakeholders, ii) adding value to the relationship with vendors, clients, distributors, and external developers and iii) expanding capabilities, e.g., marketing, support, market research, and technological decisions based on its partners. Similarly, distributors and others stakeholders can create their profiles or Web pages and add value to their network of relations, including direct relations on an $I S V$. The most

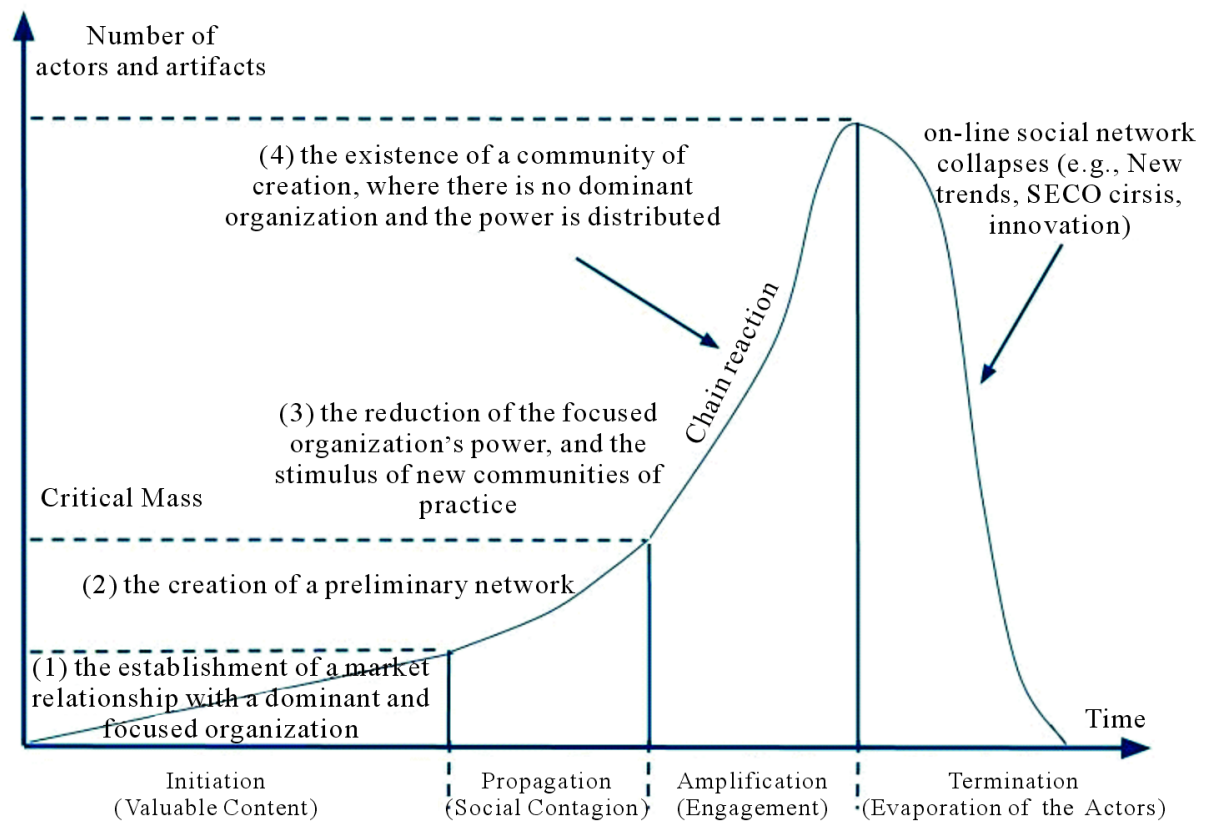

Figure 2. Relation between the use of a social network in SECOs and their lifecycle. Derived from [30]. 
important factor is the creation of content value, used to attract users in the existing social network;

2) Propagation: social contagion is under way through the adherence of new actors and artifacts. A preliminary network of actors with common interests rises: i) any person with a profile or any artifact Web pages (vendors, sellers, or other organizations); ii) maintenance of content creation, comments, and group formation (communities); iii) stimulus to participation and attraction of new members; iv) reduction of the dominant organization's power due to the opening process; and v) dominance of the super spreaders (such as market trend setters), opinion leaders and pioneers who serve as elements for innovation. At this stage, "critical mass" is reached, similarly to some nuclear chain reaction of colliding neutrons or some infectious diseases where a virus spreads through the exposure with others;

3) Amplification: establishment of a self-organizing structure and maintenance of a community engaged with (and based on) a network of SECO actors and artifacts. At this stage, the main focus is on the constant stimulus to the communities of practice, fully integrated with the dominant organization through their creations and services. Power becomes distributed, with the advantage of being in a social network site. Members can use all the functionalities and resources for communication, collaboration, recommendation and marketing, based on the publicizing and interaction;

4) Termination: usually, a service in an online social network is terminated due to saturation, or replacement with a new service, or still because new markets and trends arise. The novelty can produce an "evaporation" of the network members. It can be the result of a termination or a SECO break off.

In order to facilitate the adoption of a model for open innovation, a new player can be incorporated into the Propagation stage: the broker or hub. Technology brokers, as they are known, play the role of facilitating the meeting of supply and demand. They add the right stakeholders aiming at fomenting the support and coordinating the collaborative work among the different SECOs scope levels. This is shown in Figure 3 and in Figure 4. First of all, Figure 3 illustrates the traditional process of closed innovation, i.e., each ISV conceives its innovations within the company, which owns the platform. In this case, the ISV centralizes the main relationships with the nodes and the other relationships are underlying connections. On the other hand, Figure 4 shows the process of open innovation, through alliances that establish networks of influence, participation and interoperability among actors and artifacts, naturally generated within the SECOs. In this case, technology brokers act as mediators or evaluators of the different stakeholders with the purpose of producing reports or carry out actions. Also, all relationships are very crucial for the SECO.

Finally, Figure 5 presents a proposal of a sociotechnical based architecture to support the SECOs lifecycle, derived from a proposal by Santos \& Werner [9]. It consists in i) providing an environment to work with the social lifecycle of the SECOs, ii) considering the global SE environment, focused on the underlying sociotechnical network, and iii) make the management of the open innovation process real. This solution is centered on a data warehouse, structured around the artifacts repository involved in a SECO, i.e., applications, software components, and related services, as well as the relationships with the stakeholders (actors).

In this context, technology brokers can interfere in the development process of the SECOs platforms after exploring historical data in order to comprehend their evolution, e.g., how and when to make a platform architecture module open; how to map the market trends in the sociotechnical network by listening to the super spreaders, opinion leaders and pioneers who serve as an object

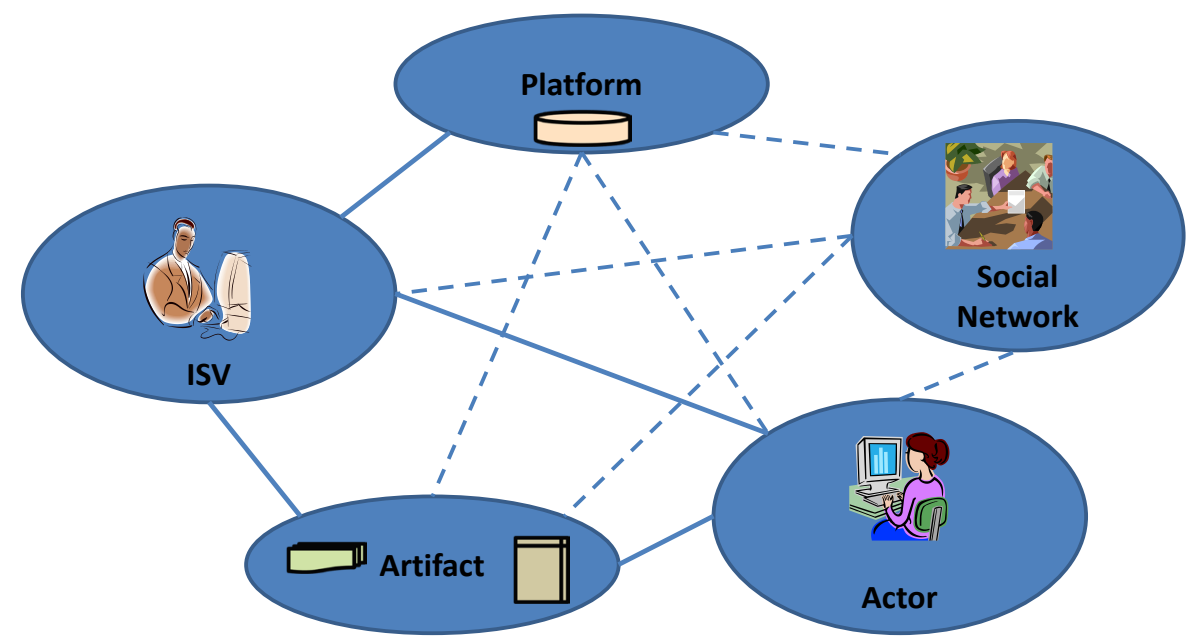

Figure 3. Innovation sources in a closed ISV. Adapted from [28]. 


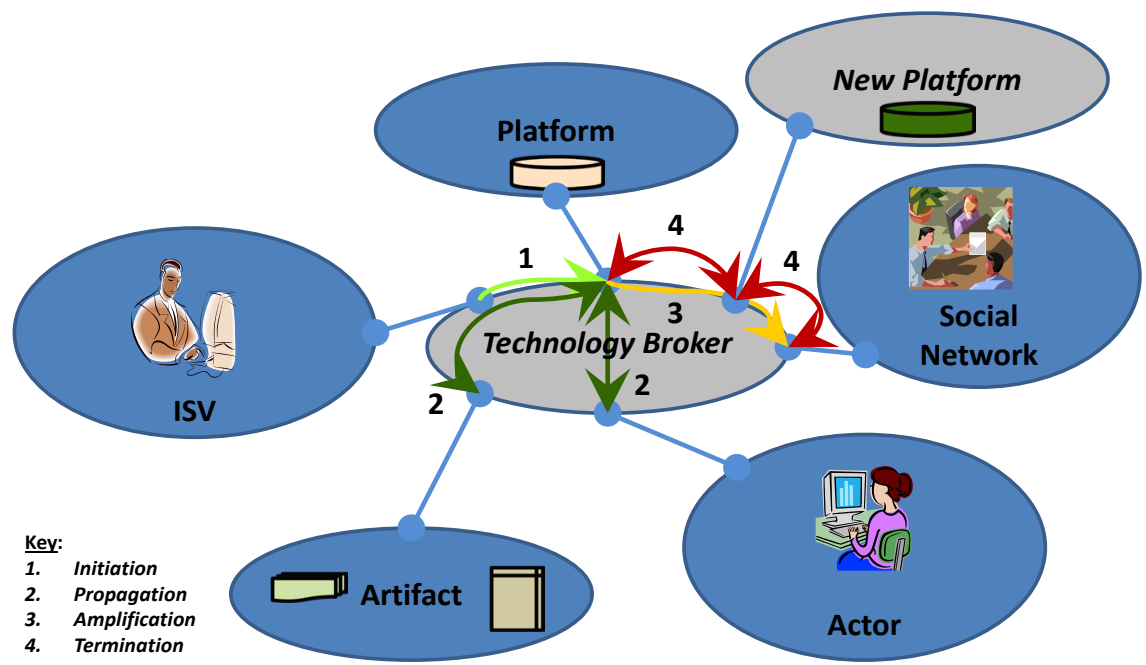

Figure 4. Innovation sources in an open SECO. Adapted from [28].

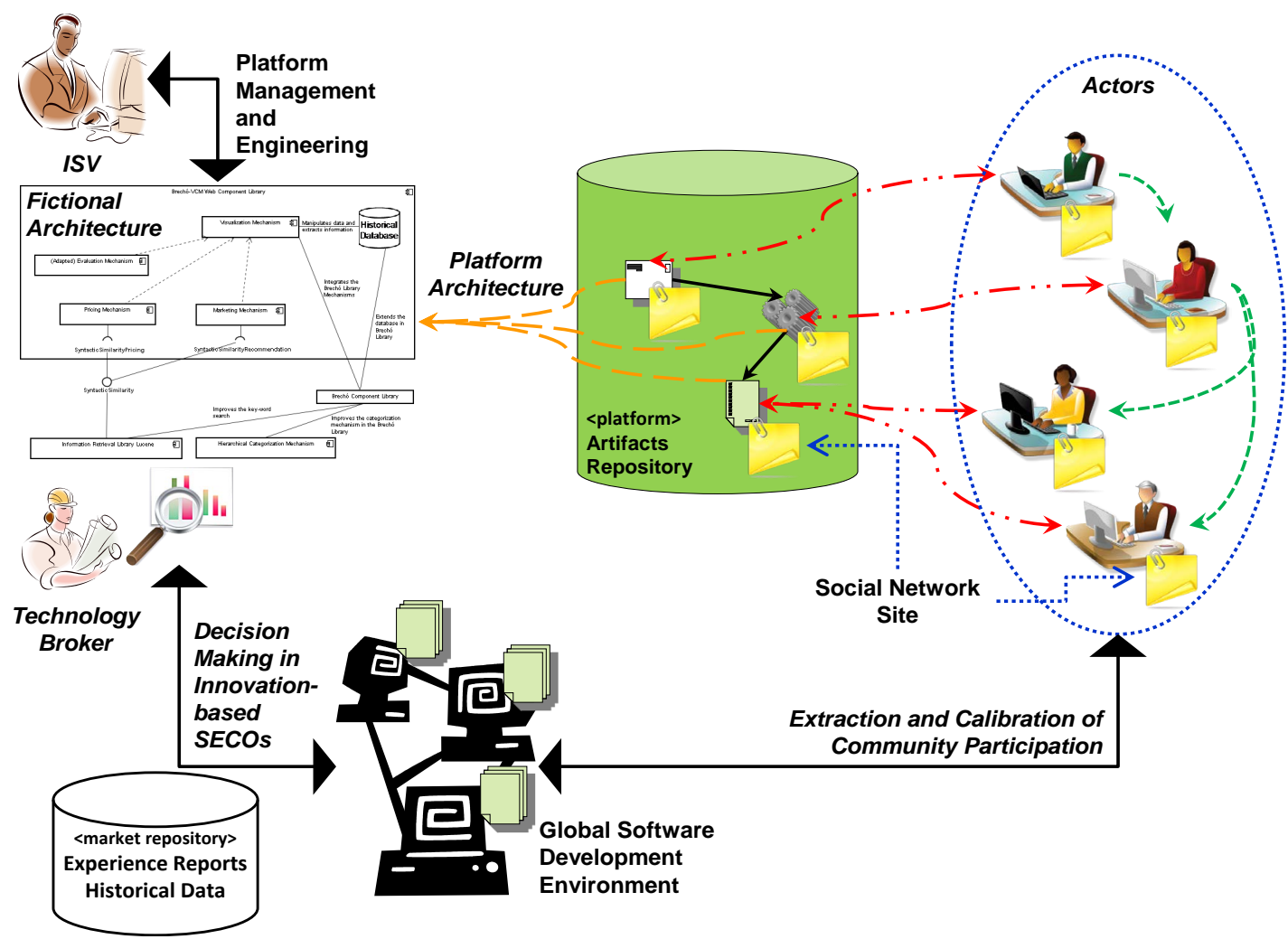

Figure 5. A sociotechnical environment for supporting SECOs lifecycle. The fictional architecture is just a draft and its detailed elements should not be syntactically or semantically considered. Derived from [9].

for innovation. Also, technology brokers can manage the utilitarianism and the promotion, based on the analysis of the external developer networks that gravitate around the SECO platform. Thus, some contributions may be valuable to SECOs health [2]: i) sustainability, i.e., the capacity to survive when actors and artifacts leave a SECO, and ii) diversity, i.e., the ability to provide opportunities of innovation and R\&D in a SECO.

\section{Conclusions}

Software development has been gradually turning to the composition of existing components developed internally by the organization, or of a commercial origin, or even through the use of FOSS or crowdsourcing (i.e., large groups of actors participating through an open call). So, SECOs have emerged as a research and practical topic in $\mathrm{SE}$ in order to treat economic and social issues in the 
software industry. In this scenario, social network sites can create a virtual environment that facilitates the adherence of new actors and artifacts and expands knowledge sharing on software components (useful to both developers and users). They also provide means to publicize and build SECO engagement, reaching a large number of vendors, clients, distributors, and third-party developers.

This paper presented an analysis of the use of social networks in SECOs through an integrated framework of the SECO and social network challenges. A proposal for a sociotechnical based architecture to support the SECOs lifecycle was also discussed. As a contribution to the social networks and SE communities, we can highlight the feasibility in researching a social SE through SECOs. As comprehension is a critical problem for SECOs, social networks research can support decision-making in software development in extending analysis and visualization techniques. As future work, 1) we intend to carry out an experimental study (survey) with specialists in SECOs to refine the proposed environment; 2) we intend to generate a second framework to assess the SECOs, position them in their lifecycle based on the social perspective; and 3) we intend to implement a tool to support this framework and the proposed environment based on an existing social network (e.g., Facebook), on an artifacts repository (e.g., Brechó [2]) and on a development tool (e.g., Eclipse) aimed at integrating it in the software development process with SECOs.

\section{Acknowledgements}

We thank CNPq, CAPES and FAPERJ (Brazil) for their financial support for this research.

\section{REFERENCES}

[1] J. Bosch, "From Software Product Lines to Software Ecosystem," Proceedings of 13th International Software Product Line Conference, San Francisco, 2009, pp. 1-10.

[2] R. P. dos Santos and C. M. L. Werner, "A Proposal for Software Ecosystems Engineering," Proceedings of the 3nd International Workshop on Software Ecosystems, 2nd International Conference on Software Business, Brussels, 2011, pp. 40-51.

[3] S. Jansen, A. Finkelstein and S. Brinkkemper, "A Sense of Community: A Research Agenda for Software Ecosystems," Proceedings of the 31st International Conference on Software Engineering, New and Emerging Research Track, Vancouver, 2009, pp. 187-190.

[4] R. P. dos Santos, C. M. L. Werner, O. A. L. P. Barbosa and C. F. Alves, "Software Ecosystems: Trends and Impacts on Software Engineering," Proceedings of the 26th Brazilian Symposium on Software Engineering, Special Track "Grand Challenges in Software/System Engineering”, Natal, 2012, pp. 206-210.

[5] R. P. dos Santos and C. M. L. Werner, "Treating Business
Dimension in Software Ecosystems," Proceedings of the 3nd ACM/IFIP International Conference on Management of Emergent Digital EcoSystems, San Francisco, 2011, pp. 197-201.

[6] R. A. C. Capuruço and L .F. Capretz, "Integrating Recommender Information in Social Ecosystems Decisions," Proceedings of the 4th European Conference on Software Architecture, 2nd International Workshop on Software Ecosystems, Copenhagen, 2010, pp. 143-150.

[7] D. Seichter, D. Dhungana, A. Pleuss and B. Hauptmann, "Knowledge Management in Software Ecosystems: Software Artifacts as First-Class Citizens," Proceedings of the 4th European Conference on Software Architecture, 2nd International Workshop on Software Ecosystems, Copenhagen, 2010, pp. 119-126.

[8] D. M. Boyd and N. B. Ellison, "Social Network Sites: Definition, History, and Scholarship,” Journal of Computer-Mediated Communication, Vol. 13, No. 1, 2007, pp. 210-230. http://dx.doi.org/10.1111/j.1083-6101.2007.00393.x

[9] R. P. dos Santos and C. M. L. Werner, "Treating Social Dimension in Software Ecosystems through ReuseSECO Approach," Proceedings of the 6th IEEE International Conference on Digital Ecosystem Technologies, Campione d'Italia, 2012, pp. 1-6.

[10] B. Latour, "Science in Action: How to Follow Scientists and Engineers through Society," Harvard University Press, Cambridge, 1988.

[11] R. P. dos Santos, M. G. P. Esteves, G. S. Freitas and J. M. Souza, "Utilizando Redes Sociais Para Apoiar os Ecossistemas de Software," Proceedings of the I Brazilian Workshop on Social Network Analysis and Mining, XXXII Brazilian Computer Society Congress, Curitiba, 2012, pp. 1-4.

[12] B. Boehm, "A View of 20th and 21st Century Software Engineering," Proceedings of the 28th International Conference on Software Engineering, Shanghai, 2006, pp. 12-29.

[13] P. R. J. Campbell and F. Ahmed, “A Three-Dimensional View of Software Ecosystems," Proceedings of the 4th European Conference on Software Architecture, 2nd International Workshop on Software Ecosystems, Copenhagen, 2010, pp. 81-84.

[14] D. G. Messerschmitt and C. Szyperski, "Software Ecosystem: Understanding an Indispensable Technology and Industry,” The MIT Press, Cambridge, 2003.

[15] V. Boucharas, S. Jansen and S. Brinkkemper, "Formalizing Software Ecosystem Modeling," Proceedings of the 1st International Workshop on Open Component Ecosystems, ACM SIGSOFT Symposium on the Foundations of Software Engineering, Amsterdam, 2009, pp. 41-50.

[16] S. Jansen, S. Brinkkemper and A. Finkelstein, "Business Network Management as a Survival Strategy: A Tale of Two Software Ecosystems," Proceedings of the 1st International Workshop on Software Ecosystems, 11th International Conference on Software Reuse, Falls Church, USA, 2009, pp. 34-48.

[17] Microsoft, "Nokia and Microsoft Brings to You 'The 3rd Ecosystem',” 2011. 
http://windows8beta.com/2011/02/nokia-and-microsoft-br ings-to-you-3rd-ecosystem

[18] D. W. McDonald, "Recommending Collaboration with Social Networks: A Comparative Evaluation,” Proceedings of the ACM Conference on Human Factors in Computing Systems, Ft. Lauderdale, 2003, pp. 593-600. http://dx.doi.org/10.1145/642611.642714

[19] M. Costa, “Análise de Redes Sociais,” Mini Paper Series 3, Technology Leadership, 2008.

[20] S. Milgram, “The Small-Word Problem,” Psychology Today, Vol. 1, No. 1, 1967, pp. 61-67.

[21] L. Backstrom, “Anatomy of Facebook,” 2011. https://www.facebook.com/notes/facebook-data-team/ana tomy-of-facebook/10150388519243859

[22] C. Allen, "Tracing the Evolution of Social Software," 2004. http://www.lifewithalacrity.com/2004/10/tracing the evo $\underline{\text { html }}$

[23] M. Perks, “Social Software-Get Real,” 2003. http://www.spiked-online.com/articles/00000006DCF1.ht $\mathrm{m}$

[24] S. Butterfield, "Social Software,” 2003. http://www.sylloge.com/personal/2003_03_01_s.html\#91 273866

[25] M. Webb, “On Social Software,” 2004.

http://interconnected.org/home/2004/04/28/on_social_soft ware

[26] WWF, "Redes: Uma Introdução às Dinâmicas da Conectividade e da Auto-organização,” Technical Report, WWF-Brasil, 2003. http://www.wwf.org

[27] H. W. Chesbrough, "Open Innovation: The New Imperative for Creating and Profiting from Technology," Harvard Business School Publishing Corporation, 2003.

[28] M. A. Schilling, "Strategic Management of Technological Innovation,” 2nd Edition, McGraw Hill, New York, 2008.

[29] A. Begel, K. Y. Phang and T. Zimmermann, "Codebook: Discovering and Exploiting Relationships in Software Repositories," Proceedings of the 32th International Conference on Software Engineering, Cape Town, 2010, pp. 125-134.

[30] C. Russ, "Online Crowds-Extraordinary Mass Behavior on the Internet,” Proceedings of the i-Media, Graz, 2007, pp. 65-76. 